\title{
Effect of incorporating the residues of Sri Lankan improved rice (Oryza sativa L.) varieties on germination and growth of barnyard grass (Echinochloa crus-galli)
}

\author{
D.L. Wathugala* and A.S. Ranagalage \\ Department of Crop Science, Faculty of Agriculture, University of Ruhuna, Mapalana, Kamburupitiya.
}

Revised: 15 July 2014; Accepted: 29 August 2014

\begin{abstract}
Crop residues, which release allelochemicals during decomposition may be able to suppress weed growth. In this study, experiments were conducted to assess the ability of crop residues of 40 commonly cultivated improved rice varieties in Sri Lanka (Oryza sativa L.) to suppress the seed germination and growth of barnyard grass (Echinochloa crus-galli). Rice crop residues were incorporated with silica sand in small pots and the experiment was conducted under greenhouse conditions. Rice cultivars exhibited marked differences in the inhibition of growth and development of barnyard grass. Ld (Labuduwa) and $\mathrm{Bw}$ (Bombuwela) rice varieties exhibited the highest inhibitory activity on the seedling growth of barnyard grass, reducing the dry weight by more than $60 \%$, while incorporation of Bw364 rice residue with sand exhibited the highest average inhibition $(44.8 \%)$ on barnyard grass seed germination and seedling growth. Ld355, Ld368 and Bw400 reduced barnyard grass seed germination and growth by more than $40 \%$. These results suggest that there is a genetic variation among the rice varieties for their ability to reduce weed germination and weed growth in paddy fields, but further analysis of allelopathic characters of rice needs to be conducted.
\end{abstract}

Keywords: Allelopathy, crop residue, Echinochloa crus-galli, improved rice cultivars, Oryza sativa L.

\section{INTRODUCTION}

Allelopathy is defined as the direct or indirect harmful or beneficial effects of one plant on another through the production of chemical compounds that escape into the environment (Rice, 1984). Chemicals released from plants, which impose allelopathic influences are termed allelochemicals, and can be present in many parts of the plant such as roots, rhizomes, leaves, stems, pollen, seeds and flowers, and are released into the environment by root exudation, leaching from aboveground parts, and volatilization and/or decomposition of plant material (Rice, 1984; Reigosa et al., 1999). This phenomenon could be used as an alternative weed control method.

Since ancient times, farmers have identified the importance of incorporating crop residues to enhance crop yields. Soil incorporation or surface application of allelopathic crop residues affects weed dynamics by reducing/delaying the seed germination and establishment, in addition to suppressing individual plant growth resulting in an overall decline in the density and vigour of the weed community (Gallandt et al., 1999). The decomposition of allelopathic crop residues produces a variety of phytotoxins in the soil causing adverse effects on other plants (Nelson, 1996). Therefore, allelopathic crop residues can be exploited for weed suppression, and can thus be helpful in reducing reliance on herbicides (Weston, 1996).

Rice (Oryza sativa L.) is the staple food of Sri Lankans and one of the most widely grown food crops in Sri Lanka. In all rice ecosystems, use of herbicides has been the most common method in weed control. However, intensive and repeated application of herbicides has resulted in various environmental problems such as environmental pollution, herbicide resistant weeds (Valverde et al., 2000), residual effects on the crop, and the disappearance of susceptible weeds, which affects weed biodiversity (Itoh, 2000). In this regard, an alternative to high dependence on herbicides is needed. Such an alternative would be the use of allelopathy, that reduces herbicide use in rice cropping systems. 
Allelopathy could be used for weed control in two ways; (1) selecting a suitable crop cultivar or incorporating allelopathic characters into a desired crop cultivar, and (2) applying the residues or straw as mulches, or growing an allelopathic cultivar in a rotational sequence (Rice, 1995).

Barnyard grass (Echinochloa crus-galli) is one of the most yield-limiting weeds in the irrigated rice systems of Sri Lanka. It is better adapted to grow under dry conditions than under wet conditions. Moreover, the paddy fields are direct seeded and frequently not under flooded conditions due to the scarcity of water, thus making conditions conducive for barnyard grass to grow. As a result this weed is expected to cause a greater problem in the future (Im et al., 1993).

The use of allelopathy is therefore an environmentally acceptable and sustainable approach to control barnyard grass and other paddy weeds. A number of studies have been conducted to evaluate the allelopathic potential of rice germplasm and a number of rice accessions having allelopathic potential have been identified in different studies (Fujii, 1992; Garrity et al., 1992; Lin et al., 1992; Dilday et al., 1994; Hassn et al., 1994; Olofsdotter et al., 1995; Chou, 1995; 1999; Chung et al., 1997; Ahn \& Chung, 2000). As an example Dilday et al. (1998) identified 412 accessions having allelopathic potential against ducksalad [Heteranthera limosa (Sw.) Willd.] among 12000 accessions from 31 different countries. The above studies demonstrated the widespread allelopathic potential of the rice germplasm. It is assumed that rice allelopathy may be polygenetically controlled because it shows a continuous variation in the germplasm (Kim \& Shin, 2003). Moreover, allelopathic potential is often attributed to several inhibitors that are assumed to act in an additive or synergistic way rather than in an isolated way (Courtois \& Olofsdotter, 1998). Dilday et al. (1989; 1991) have shown that the japonica type rice had higher allelopathic activity than javonica rice. Fujii (1993) has observed that red rice ( $O$. sativa L.) accessions and African rice varieties (O. glaberima L.) have a higher allelopathic activity. The allelopathic potential of rice residues has also been studied (Chung et al., 2001a; 2001b; 2002) and several allelochemicals have been extracted. The extracts of the residues of various parts of 114 rice varieties such as hull, straw and leaves were found to suppress barnyard grass seed germination and growth (Chang et al., 2003). They also showed variations in allelopathic activity according to the origin, maturity time, hull colour and awn colour. Although allelopathic research has been conducted for several decades, the knowledge available is limited. In Sri Lanka, a large number of improved and traditional rice varieties are cultivated but their allelopathic potential have not been evaluated. Therefore, the present study was carried out to assess the ability of crop residues of commonly cultivated Sri Lankan rice varieties to suppress the seed germination and seedling growth of barnyard grass. The changes in barnyard grass suppressive ability according to rice plant's maturity age and pericarp colour was also analyzed.

\section{METHODS AND MATERIALS}

Forty (40) improved rice varieties were collected from 4 regional rice breeding stations, namely, Bombuwela-Bw, Bathalagoda-Bg, Ambalanthota-At and Labuduwa-Ld. The cultivars were grown from November 2012 to January 2013 at the Faculty of Agriculture, University of Ruhuna and harvested after maturation in March 2013. The harvested plants were dried at room temperature $\left(28^{\circ} \mathrm{C}\right)$ and the leaves and stem parts were ground into a fine powder. Residue mixtures were prepared according to the method described by Jung et al. (2004), but steam sterilization of the residue mixture was not practiced. Three grams of the residue was mixed thoroughly with $300 \mathrm{~g}$ of silica sand in each pot (diameter $9 \mathrm{~cm}$ and height $10 \mathrm{~cm}$ ) to prepare a $1 \%$ (w/w) rice residue mixture. Fifty barnyard grass seeds (50) were planted uniformly, $1 \mathrm{~cm}$ deep in each pot 2 wks after residue incorporation. Seedling emergence was defined as the coleoptile protrusion through the soil surface and was counted each day for 10 days after planting. After emergence, the seedlings were thinned to 20 plants per pot. Water was added to each pot to maintain adequate moisture. The pots were arranged in a randomized complete block design in three replicates. All the plants were harvested 20 days after planting (DAP) and the plants in each pot were measured for shoot length and the number of leaves. The seedlings were then dried at $65{ }^{\circ} \mathrm{C}$ for $8 \mathrm{~h}$ for dry weight determination. Control plants were grown in silica sand without the residue. The inhibitory percentage was calculated using the following equation.

The overall inhibition percentage for each cultivar studied was computed by averaging the inhibition percentages of each trait investigated; seed germination (GP), number of leaves (NL), shoot length (SL), dry weight (DW) and rate of seed germination (GR). The rate of seed germination was calculated according to Maguire (1962).

$$
\mathrm{GR}=\sum \mathrm{Dn} / \sum \mathrm{n}
$$


Percentage inhibition $(\%)=\frac{\text { control value }- \text { residue mixture value } \times 100}{\text { control value }}$

where, D is the number of days counted from the beginning of sprouting and $\mathrm{n}$ is the number of newly emerged seeds on day D.

The experiment was conducted twice in three replicates in a randomized complete block design in a greenhouse at an average temperature of $28^{\circ} \mathrm{C}$. F test was conducted to analyze the variance of each test. Analysis of variance for all data was done by general linear model procedure of the statistical analysis system (SAS). The pooled mean values were separated on the basis of least significant difference (LSD) at 0.05 probability level.

\section{RESULTS}

The percentage inhibition of seed germination (GP), shoot length (SL), number of leaves (NL), seedling dry weight (DW) and rate of germination (GR) of barnyard grass caused by the 40 rice residue mixtures are given in Table 1. Data showed marked differences in the inhibitory effect of the measured parameters of barnyard grass. Inhibition of DW was greater than that of the other measured parameters (Table 1). Bw351 showed the highest $(89.1 \%)$ allelopathic potential and Bg359 the lowest (38.5\%) based on dry matter accumulation in barnyard grass (Table 1). Rice variety Bg403 showed the highest inhibitory effect on barnyard grass seed germination (27\%), whereas the lowest inhibition (2.9\%) was observed with At308. Ld368 and Bw400 showed the highest inhibitory effect on shoot length $(56.5 \%)$ and the number of leaves $(55.3 \%)$, respectively. Conversely, Bg305, At354, At306 and Bg304 stimulated the shoot growth of barnyard grass where $\mathrm{Bg} 304$ residue mixture caused the highest $(10.3 \%)$ stimulation. The average inhibition potential on barnyard grass was the highest in Bw364 (44.8 \%) and lowest in At306 (7.1\%).

Based on average inhibition percentages the rice cultivars were classified into 5 groups. The first group consisted of varieties producing $40 \%$ or greater inhibition and the group contained 4 varieties including two $\mathrm{Ld}$ ( $\mathrm{Ld} 355$ and $\mathrm{Ld} 368$ ) varieties and two $\mathrm{Bw}$ (Bw400 and Bw364) varieties, while 20 varieties were grouped in the second group, which produced $39-30 \%$ inhibition including three $\mathrm{Ld}$ varieties. The third group consisted $29-20 \%$ inhibition and comprised 14 rice varieties, while the other two groups produced $19-10 \%$ and less than $10 \%$ inhibition, which comprised one variety each (Table 2 and Figure 1).
There are enough evidence that the allelopathic activity of rice varieties and their residues differed according to the type (Dilday et al., 1991), origin (Chung et al., 2003), pericarp colour (Fujii, 1993), hull colour (Chung et al., 2003), maturity time (Chung et al., 2003) and awn colour (Chung et al., 2003). Therefore in this study, the results have been analysed to examine the variations of allelopathic activity according to maturity age and pericarp colour. The average inhibition percentage with maturity group was significantly higher $(35.4 \%)$ in $4 \frac{1}{2}$ month varieties, while it was lower $(27.2 \%)$ in 3 month varieties (Table 3 ). The average inhibition with pericarp colour (white or brown) was $29.6 \%$ for white rice and $35 \%$ for brown rice. Brown rice showed significantly higher inhibition percentages except in the germination percentage (Table 4).

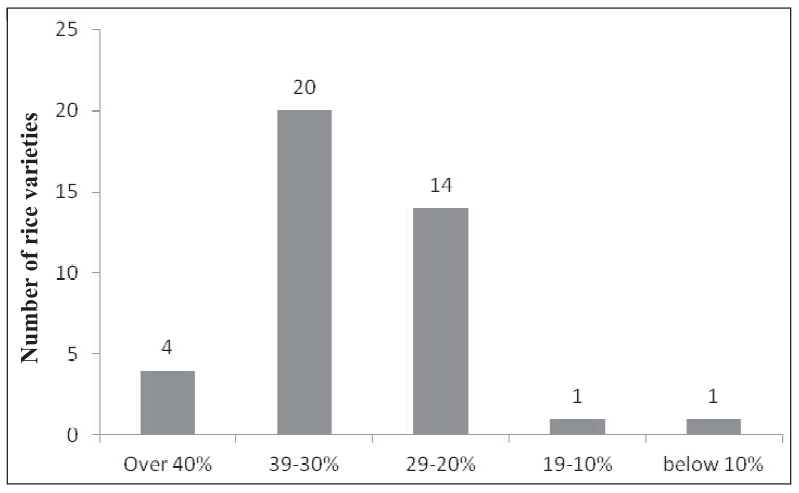

Figure 1: Number of rice varieties with different allelopathic potential in rice residue mixtures on barnyard grass seedling growth

\section{DISCUSSION}

A critical look into the data obtained confirmed the inhibitory effect of rice crop residues on germination and seedling growth of barnyard grass (Table 1). These suppressive actions are believed to originate from the toxic compounds released from the residues, or produced by microorganism activity during residue decomposition (Birkett et al., 2001). As different plant species contain various allelochemicals in various concentrations (Xuan et al., 2004), the degree of growth inhibition observed in this experiment may also be the result of variations in the type and concentrations of allelochemicals among rice varieties. When susceptible plants are exposed to allelochemicals, the seed germination, 
Table 1: The inhibitory effect of forty (40) rice variety residue mixtures on barnyard grass seedling growth, germination, and germination rate ${ }^{a}$

\begin{tabular}{|c|c|c|c|c|c|c|c|c|}
\hline \multirow[t]{2}{*}{ Cultivar name } & \multicolumn{7}{|c|}{ Percent inhibition } & \multirow[b]{2}{*}{ Average } \\
\hline & DR & $\mathrm{PC}$ & GP & SL & $\mathrm{LN}$ & DW & GR & \\
\hline $\mathrm{Bg} 38$ & 5 & $\mathrm{~W}$ & 19.6 & 2.8 & 24.5 & 59.0 & 28.2 & 26.8 \\
\hline Bg $407-\mathrm{H}$ & 5 & $\mathrm{~W}$ & 14.2 & 6.1 & 20.8 & 47.7 & 32.7 & 24.3 \\
\hline $\mathrm{Bg} 3-5$ & 5 & $\mathrm{~W}$ & 21.0 & 35.5 & 36.5 & 54.6 & 34.7 & 36.4 \\
\hline Bw 452 & 4.5 & $\mathrm{R}$ & 17.6 & 35.9 & 43.4 & 55.5 & 38.0 & 38.1 \\
\hline Bw 451 & 4.5 & $\mathrm{~W}$ & 16.2 & 29.7 & 39.6 & 54.1 & 41.8 & 36.3 \\
\hline Bw453 & 4.5 & $\mathrm{~W}$ & 21.6 & 34.4 & 42.8 & 58.4 & 36.0 & 38.7 \\
\hline $\mathrm{Bg} 454$ & 4.5 & $\mathrm{~W}$ & 16.1 & 30.0 & 34.0 & 54.6 & 33.8 & 33.7 \\
\hline Ld408 & 4 & $\mathrm{R}$ & 16.9 & 28.2 & 25.8 & 53.2 & 36.6 & 32.1 \\
\hline Bw 400 & 4 & $\mathrm{R}$ & 15.0 & 32.3 & 55.3 & 59.1 & 40.9 & 40.5 \\
\hline $\mathrm{H}-4$ & 4 & W & 23.0 & 12.1 & 24.5 & 81.3 & 36.2 & 35.4 \\
\hline Bg 406 & 4 & $\mathrm{R}$ & 15.7 & 37.4 & 33.3 & 51.3 & 31.5 & 33.8 \\
\hline $\mathrm{Bg} 407$ & 4 & W & 18.9 & 10.8 & 22.6 & 42.5 & 29.0 & 24.8 \\
\hline At402 & 4 & $\mathrm{R}$ & 18.3 & 4.4 & 23.9 & 63.3 & 32.4 & 28.5 \\
\hline At 401 & 4 & $\mathrm{R}$ & 17.9 & 12.1 & 23.3 & 48.9 & 38.8 & 28.2 \\
\hline At 405 & 4 & W & 15.9 & 15.7 & 23.9 & 60.5 & 40.0 & 31.2 \\
\hline $\mathrm{Bg} 403$ & 4 & W & 27.0 & 17.1 & 22.0 & 56.1 & 29.3 & 30.3 \\
\hline Bw 267-3 & 3.5 & W & 15.7 & 23.4 & 39.6 & 59.4 & 37.4 & 35.1 \\
\hline Bw 361 & 3.5 & $\mathrm{R}$ & 13.5 & 30.9 & 34.6 & 55.8 & 34.9 & 34.0 \\
\hline Bw 363 & 3.5 & W & 12.2 & 12.9 & 23.3 & 57.4 & 32.3 & 27.6 \\
\hline Bw 367 & 3.5 & W & 14.0 & 6.4 & 26.4 & 60.5 & 40.0 & 29.5 \\
\hline Ld356 & 3.5 & $\mathrm{R}$ & 11.0 & 19.7 & 24.5 & 69.0 & 37.8 & 32.4 \\
\hline Ld368 & 3.5 & $\mathrm{R}$ & 13.7 & 56.5 & 39.6 & 61.9 & 41.1 & 42.5 \\
\hline Ld355 & 3.5 & W & 14.7 & 43.0 & 43.4 & 64.7 & 44.7 & 42.1 \\
\hline Bw364 & 3.5 & $\mathrm{R}$ & 18.3 & 37.2 & 43.4 & 85.8 & 39.3 & 44.8 \\
\hline At 362 & 3.5 & $\mathrm{R}$ & 18.9 & 44.0 & 41.5 & 59.0 & 34.5 & 39.6 \\
\hline Bw272-6b & 3.5 & $\mathrm{R}$ & 15.6 & 22.3 & 23.9 & 49.1 & 32.3 & 28.6 \\
\hline Bw351 & 3.5 & W & 19.6 & 4.0 & 25.8 & 89.1 & 38.8 & 35.5 \\
\hline Bg 360 & 3.5 & W & 24.3 & 1.1 & 23.9 & 53.6 & 26.7 & 25.9 \\
\hline At353 & 3.5 & W & 18.3 & 2.7 & 24.5 & 52.7 & 34.3 & 26.5 \\
\hline $\operatorname{Bg} 359$ & 3.5 & W & 14.2 & 18.3 & 22.6 & 38.5 & 33.8 & 25.5 \\
\hline At354 & 3.5 & W & 19.6 & -14.6 & 11.9 & 67.5 & 33.0 & 23.5 \\
\hline $\mathrm{Bg} 358$ & 3.5 & W & 20.8 & 9.4 & 17.6 & 44.3 & 32.6 & 24.9 \\
\hline $\operatorname{Ld} 365$ & 3.5 & $\mathrm{R}$ & 16.2 & 20.6 & 21.2 & 77.0 & 34.3 & 33.9 \\
\hline At 308 & 3 & W & 2.9 & 42.4 & 43.4 & 82.9 & 26.4 & 39.6 \\
\hline Bg 305 & 3 & W & 20.3 & -7.5 & 23.3 & 83.9 & 30.7 & 30.1 \\
\hline At306 & 3 & W & 17.6 & -14.7 & 5.0 & -5.7 & 33.1 & 7.1 \\
\hline $\mathrm{Bg} 304$ & 3 & W & 15.7 & -18.3 & 5.7 & 50.6 & 33.8 & 17.5 \\
\hline At 307 & 3 & W & 10.1 & 14.4 & 25.2 & 54.3 & 30.2 & 26.8 \\
\hline At303 & 3 & $\mathrm{R}$ & 16.1 & 30.1 & 32.7 & 56.5 & 31.9 & 33.5 \\
\hline Bw302 & 3 & W & 23.2 & 32.4 & 43.4 & 53.1 & 34.8 & 37.4 \\
\hline $\mathrm{CV}$ & & & 18.5 & 6.9 & 8.9 & 2.5 & 15.6 & 2.3 \\
\hline $\operatorname{LSD}(0.05)$ & & & 5.0 & 0.7 & 4.2 & 0.3 & 8.8 & 0.2 \\
\hline
\end{tabular}

${ }^{\text {a }} \mathrm{DR}$ - duration in months; PC - pericarp colour; R - varieties with red coloured pericarp; W - varieties with white coloured pericarp; GP - germination percentage; SL - shoot length; LN - leaf number; DW - dry weight; GR - germination rate

$\mathrm{CV}$ - coefficient of variance; LSD - least significant difference 
Table 2: Distribution of rice varieties with allelopathic potential of rice residue mixtures and extracts on barnyard grass seedling growth

\begin{tabular}{ll}
\hline Total inhibition $\%$ & Varieties \\
\hline Over $40 \%$ & Ld355, Ld368, Bw400, Bw364 \\
$39-30 \%$ & Ld356, Ld408, Ld365, Bw452, Bw302, \\
& Bw267-3, Bw451, Bw361, Bw453, Bw351, \\
& H-4, Bg406, Bg454, Bg3-5, Bg403, Bg305, \\
& At303, At362, At308, AT405 \\
& Bw363, Bw367, Bw272-6b, Bg 360, Bg407, \\
$29-20 \%$ & Bg359, Bg407-H, Bg358, Bg38, At353, \\
& At307, At402, At401, At354 \\
$19-10 \%$ & Bg304 \\
Below $10 \%$ & At306 \\
\hline
\end{tabular}

Table 3: Inhibition percentages of barnyard grass by residue mixtures in varieties with different maturity times

\begin{tabular}{lcccccc}
\hline $\begin{array}{l}\text { Maturity } \\
\text { group }\end{array}$ & GP & SL & LN & DW & GR & Average \\
\hline & & & & & & \\
$5 \mathrm{M}$ & $16.7^{\mathrm{ab}}$ & $12.9^{\mathrm{c}}$ & $28.3^{\mathrm{c}}$ & $53.6^{\mathrm{c}}$ & $34.2^{\mathrm{ab}}$ & $29.1^{\mathrm{d}}$ \\
$4.5 \mathrm{M}$ & $17.7^{\mathrm{ab}}$ & $30.6^{\mathrm{a}}$ & $37.4^{\mathrm{a}}$ & $54.3^{\mathrm{c}}$ & $37.1^{\mathrm{a}}$ & $35.4^{\mathrm{a}}$ \\
$4 \mathrm{M}$ & $18.5^{\mathrm{a}}$ & $20.0^{\mathrm{b}}$ & $28.9^{\mathrm{b}}$ & $57.1^{\mathrm{b}}$ & $34.8^{\mathrm{ab}}$ & $31.8^{\mathrm{c}}$ \\
$3.5 \mathrm{M}$ & $16.0^{\mathrm{b}}$ & $21.0^{\mathrm{b}}$ & $29.3^{\mathrm{b}}$ & $62.8^{\mathrm{a}}$ & $36.6^{\mathrm{a}}$ & $33.2^{\mathrm{b}}$ \\
$3 \mathrm{M}$ & $16.3^{\mathrm{ab}}$ & $10.0^{\mathrm{d}}$ & $25.3^{\mathrm{d}}$ & $53.7^{\mathrm{c}}$ & $31.0^{\mathrm{b}}$ & $27.2^{\mathrm{e}}$ \\
& & & & & & \\
CV & 7.2 & 8.4 & 4.1 & $0.7^{\circ}$ & 6.3 & 1.7 \\
LSD & 2.2 & 2.9 & 2.2 & $0.7^{7}$ & 4.0 & 1.0 \\
$(0.05)$ & & & & & & \\
\hline
\end{tabular}

$5 \mathrm{M}$ - five months; $4.5 \mathrm{M}$ - four and half months; $4 \mathrm{M}$ - four months; $3.5 \mathrm{M}$ - three and half months; $3 \mathrm{M}$ - three months

GP - germination percentage; SL - shoot length; LN - leaf number; DW - dry weight; GR - germination rate

$\mathrm{CV}$ - coefficient of variance; LSD - least significant difference

Table 4: Effect of white and brown rice residue mixtures on inhibition percentages of barnyard grass

\begin{tabular}{lcccccc}
\hline Residue & \multicolumn{5}{c}{ Percent inhibition } \\
mixture & GP & SL & NL & DW & GR & Total \\
\hline White rice & $17.5^{\text {a }}$ & $14.3^{\text {b }}$ & $27.0^{\text {b }}$ & $55.6^{\text {b }}$ & $33.8^{\text {b }}$ & $29.6^{\text {b }}$ \\
Brown rice & $16.0^{\text {b }}$ & $29.4^{\text {a }}$ & $33.3^{\text {a }}$ & $60.4^{\text {a }}$ & $36.0^{\text {a }}$ & $35.0^{\text {a }}$ \\
& & & & & & \\
CV & 1.6 & 3.6 & 3.4 & 0.6 & 3.9 & 1.3 \\
LSD $(0.05)$ & 0.6 & 1.7 & 2.3 & 0.9 & 3.1 & 0.7 \\
\hline
\end{tabular}

GP - germination percentage; SL - shoot length; LN - leaf number; DW - dry weight; GR - germination rate

$\mathrm{CV}$ - coefficient of variance; LSD - least significant difference growth and development etc., may be affected. The most frequently reported gross morphological effects on plants are the inhibited or retarded seed germination, effects on coleoptile elongation and on radicle, shoot and root development (Kruse et al., 2000). Chung et al. (1997), Olofsdotter et al. (1995), Dilday et al. (1994) and Ahn and Chung (2000) have conducted several experiments using rice residue extracts and rice residues incorporated with silica sand, to compare the allelopathic characteristics of various rice varieties. The results have shown that variations in allelopathic activity exist among the tested rice varieties. A study conducted by Khan and Vaishya (1992) also reported that rice residues in soil can inhibit the population and biomass of Echinochloa colona. The difference in response was attributed to the genetic differences among the varieties, since the amount of rice residue incorporated were the same. However, this allelopathic activity can be a result of higher concentrations of the same chemical or a combination of different chemicals. There are possibilities that decomposing rice residues produce different amounts of one or more allelopathic substances. Chung et al. (2001a) has extracted nine known allelochemicals and their mixtures from rice straw extracts by high performance liquid chromatography (HPLC) analysis. Chou (1995; 1999) has also identified several allelopathic chemicals such as p-hydroxybenzoic acid, ferulic acid, p-coumaric syringic acid and salicylic acid from rice leaves and straw extracts, decomposing straw and rice soil.

Allelopathic potential would be a valuable trait to incorporate into rice cultivars for improved weed management. Among the rice varieties used in this study Ld and Bw varieties showed comparatively higher inhibition percentages except in seed germination inhibition (Table 1). Therefore these varieties may have important gene resources for breeding rice for higher allelopathic potential. The inhibitory percentages significantly changed with maturity time. Four and half month varieties showed the highest average inhibition percentages (Table 3 ), but 5 month varieties showed a lower inhibition than $3 \frac{1}{2}$ month varieties indicating that there is no interaction with maturity time and growth inhibition of barnyard grass. Four $4 \frac{1}{2}$ month varieties have been used for this experiment and out of them 3 varieties are Bw varieties, which showed higher percentage of inhibition on barnyard grass seed germination and growth. Therefore average inhibition by $4 \frac{1}{2}$ month varieties may have given higher values. Further experiments using more varieties with different origins is important before coming to a final conclusion. These results further indicate that allelopathic characters are attributed to genetic differences of rice varieties. Significant inhibition percentages were observed in 
brown rice varieties compared to white rice except in the inhibition of seed germination (Table 4) and these results indicate that brown rice varieties have higher allelopathic potential than white rice varieties. There is a belief that varieties with coloured pericarps have higher nutraceutucal properties than white rice. Some experimental evidences also show that brown rice contains more nutrients and antioxidents than white rice (Wathugala, 2014). Jung et al. (2004) showed that rice residues of varieties with coloured hull have higher allelopathic potential on barnyard grass compared to varieties with colourless hull.

Four rice varieties showed stimulatory effects on shoot length and inhibitory effects on all other measured parameters, and one variety (At306) showed stimulatory effects on dry weight (Table 1). Rice (1984) reported that stimulatory effects may happen at low concentrations of allelopathic substances but inhibitory effects at higher concentrations. Therefore these varieties may have released very low amounts of allelochemicals during decomposition and the residues may decompose quickly and release plant nutrients to enhance barnyard grass growth. Out of the 40 varieties tested in this experiment all varieties except two (Bg304 and At306) showed more than $20 \%$ average inhibition on barnyard grass growth, indicating the importance of residue incorporation to paddy soil. In this experiment $1 \%$ of rice residue was incorporated to prepare the soil mixture. Therefore, $4714 \mathrm{~kg} \mathrm{ha}^{-1}$ of rice residue $(3 \times 7 \times 4 \times 108 / 22 \times 81 \times$ $103 \mathrm{~kg} \mathrm{ha}^{-1}$ for $10 \mathrm{~cm}$ deep of soil) would be theoretically required for allelopathy to occur in the field. However many factors other than the amount of residue may also be involved in allelopathic activity such as soil conditions, climatic conditions and management conditions. Also, allelochemicals released from decomposing straw may not remain active for long under field conditions due to further microbial activity. Therefore, different results would be expected in field conditions. However, according to the results obtained in this study, the more rice residues remaining in the paddy soil, the greater the concentration of allelopathic substances released during decomposition and higher degree of weed control. Some Sri Lankan farmers leave all the residues (straw) in the field but some farmers still burn rice residues (straw) before field preparation for the next season. Weeds can be better controlled by incorporating plant residues that release a greater fraction of allelochemicals in the soil (Elijarrat \& Barcelo, 2001). Therefore, improving the allelopathic properties of commonly cultivated rice varieties can be used as an eco-friendly approach to combat paddy weed problem by reducing herbicide usage.
In Sri Lanka, the farmers mainly cultivate improved rice varieties but information on allelopathic potential of these rice varieties are lacking. This study provides information to develop rice varieties with higher allelopathic activity and also suggests that the allelopathic compounds released when rice residues (straw) decompose can act as a natural herbicide to control weeds. Therefore, incorporating rice residues (straw) to paddy soil can be used to reduce the cost of weed control in direct seeded rice ecosystems. However, further studies need to be conducted to evaluate the suppressive effect of rice residues applied under natural conditions.

\section{CONCLUSION}

The incorporation of crop residues help to reduce the effectiveness of barnyard grass. The results revealed that the ability to inhibit germination and growth of barnyard grass differ among the rice varieties used. The inhibitory effect of $\mathrm{Ld}$ and $\mathrm{Bw}$ varieties are superior than $\mathrm{Bg}$ and At varieties. Therefore, isolation and identification of allelochemicals from rice straw and studying the effect of allelochemicals on germination and growth of weeds are important for further analysis of allelopathic characters of rice varieties.

\section{Acknowledgement}

The authors wish to acknowledge the financial support from the Transforming University of Ruhuna to International Status (TURIS) project for this experiment.

\section{REFERENCES}

1. Ahn J.K. \& Chung I.M. (2000). Allelopathic potential of rice hulls on germination and seedling growth of barnyard grass. Agronomy Journal 92: 1162 - 1167.

DOI: http://dx.doi.org/10.2134/agronj2000.9261162x

2. Birkett M.A., Chamberlein K., Hooper A.M. \& Pickett J.A. (2001). Does allelopathy offer real promise for practical weed management and for explaining rhizosphere interactions involving higher plants. Plant and Soil 232: 31 -39 .

DOI: http://dx.doi.org/10.1023/A:1010325801256

3. Chou C.H. (1995). Allelopathy and sustainable agriculture. allelopathy; organisms, process, and application. ACS Symposium Series $S 82$ (eds. K.M.M. Inderjit Dakshini \& F.A. Einhellig), pp. $211-223$. American Chemical Society, Washington DC, USA.

4. Chou C.H. (1999). Role of allelopathy in plant biodiversity and sustainable agriculture. Critical Reviews in Plant Sciences 18: $609-636$. 
5. Chung I.M., Kim K.H., Ahn J.K. \& Ju H.J. (1997). Allelopathic potential evaluation of rice cultivars on Echinochloa crus-galli. Korean Journal of Weed Science 17: $52-58$.

6. Chung I.M., Ahn J.K. \& Yun S.J. (2001a). Identification of allelopathic compounds from rice (Oryza sativa L.) straw and their biological activity. Canadian Journal of Plant Science 81: $815-819$.

DOI: http://dx.doi.org/10.4141/P00-191

7. Chung I. M., Ahn J. K. \& Yun S. J. (2001b). Assessment of allelopathic potential of barnyard grass (Echinochloa crusgalli) on rice (Oryza sativa L.) cultivars. Crop Protection 20: 921 - 928 .

8. Chung I.M., Kim K.H., Ahn J.K., Chun S.C., Kim C.S., Kim J.T. \& Kim S.H. (2002). Screening of allelochemicals on barnyard grass (Echinochloa crus-galli) and identification of potentially allelopathic compounds from rice (Oryza sativa) variety hull extracts. Crop Protection 21: $913-920$.

9. Chung I.M., Kim K.H., Ahn J.K., Lee S.B., Kim S.H. \& Hahn S.J. (2003). Comparison of allelopathic potential of rice leaves, straw, and hull extracts on Barnyard grass. Agronomy Journal 95: 10063 - 10070.

DOI: http://dx.doi.org/10.2134/agronj2003.1063

10. Courtois B. \& Olofsdotter M. (1998). Incorporating the allelopathy trait in upland rice breeding programs. Allelopathy in Rice (ed. M. Olofsdotter), pp. $57-68$. International Rice Research Institute, Manila, The Philippines.

11. Dilday R.H., Nastasi F. \& Smith Jr. R.J. (1989). Potential allelopathic activity of rice (Oryza sativa L.) germplasm. Southern Weed Science Society Proceedings 42: 261.

12. Dilday R.H., Nastasi F. \& Smith Jr. R.J. (1991). Allelopathic activity in rice (Oryza sativa L.) against Ducksalad (Heteranthera limosa Wild.). In: Symposium Proceedings on Sustainable Agriculture for the Great Plains (eds. J.D. Hunsan, M.J. Shaffer, D.A. Ball \& C. Vern Cole). 19- 20 January 1989, pp. $193-201$.

13. Dilday R.H., Lin J. \& Yan W. (1994). Identification of allelopathy in the USDA-ARS rice germplasm collection. Australian Journal of Experimental Agriculture 34: 907 910.

DOI: http://dx.doi.org/10.1071/EA9940907

14. Dilday R.H., Yan W.G., Moldenhauer K.A.K. \& Gravois K.A. (1998). Allelopathic activity in rice for controlling major aquatic weeds. Allelopathy in rice (ed. M. Olofsdotter), pp. 7 - 26. International Rice Research Institute, Manila, The Philippines.

15. Elijarrat E. \& Barcelo D. (2001). Sample handling and analysis of allelochemical compounds in plants. Trends in Analytical Chemistry 20: 584 - 590.

16. Fujii Y. (1992). The potential biological control of paddy weeds with allelopathy-allelopathic effect of some rice cultivars. Proceedings of the International Symposium on Biological Control and Integrated Management of Paddy and Aquatic Weeds, Tsukuba, Japan, pp. $305-320$.

17. Fujii Y. (1993). The allelopathic effect of some rice varieties. Allelopathy in control of paddy weeds. Technical Bulletine
134, pp. 1 - 6. ASPAC Food and Fertilizer Technology Center, Taiwan.

18. Gallandt E.R., Liebman M. \& Huggins D.R. (1999). Improving soil quality: implications for weed management. Journal of Crop Production 2: 95 - 121.

DOI: http://dx.doi.org/10.1300/J144v02n01_06

19. Garrity D.P., Movillon M. \& Moddy K. (1992). Differential weed suppression ability in upland rice cultivars. Agronomy Journal 84: 586 - 591.

20. Hassn S.M., Rao A.N., Bastawisi A.O. \& Aidy I.R. (1994). Weed management in broadcast seeded rice in Egypt. constraints, opportunities and innovations for wet-seeded rice. IRRI Discussion Paper Series 10 (ed. K. Moddy), pp. 257 - 269. International Rice Research Institute, Manila, The Philippines.

21. Im I.B., Guh O.J. \& Oh Y.J. (1993). Weed occurrence and competitive characteristic under different cultivation types of rice (Oryza sativa L.). 3. difference in weed occurrence and rice growth under the competitive periods. Korean Journal of Weed Science 13: 114 - 121.

22. Itoh K. (2000). Importance of biodiversity of aquatic plants in agro-ecosystem for rice production. Abstracts of the International Symposium on Weed Biodiversity National Sun Yat-sen University, Kaohsiung, Taiwan, 28 - 30 November, Weed Science Society of the Republic of China and National Sun Yat-sen University, Kaoshing, Taiwan, p. 10.

23. Jung W.S., Kim K.H., Ahn J.K., Hahn S.J. \& Chung I.M. (2004). Allelopathic potential of rice (Oryza sativa L.) residues against Echinochloa crus-galli. Crop Protection 23: $211-218$.

24. Khan A.H. \& Vaishya R.D. (1992). Allelopathic effects of different crop residues on germination and growth of weeds. Proceedings of the First National Symposium in Allelopathy in Agroecosystems (Agriculture \& Forestry) (ed. P. Tauro \& S.S Narwal). Indian society of Allelopathy, Haryana Agricultural University, Hisar, India, pp. 59-60.

25. Kim K.U. \& Shin D.H. (2003). The importance of allelopathy in breeding new cultivars. weed management for developing countries. FAO Plant Production and Protection Paper No. 120 (addendum 1) (ed. R. Labrada), pp. 195 210. Food and Agriculture Organization, Rome, Italy.

26. Kruse M., Strandberg M. \& Strandberg B. (2000). Ecological effects of allelopathic plants - a review. NERI Technical Report No. 315, pp. 66. National Environmental Research Institute, Silkeborg, Denmark.

27. Lin J., Smith Jr. R.J. \& Dilday R.H. (1992). Comparison of allelopathic rice and bensulfuron for aquatic weed control in rice. Western Aquatic Plant Management Society Abstracts 33: 170 .

28. Maguire J.D. (1962). Speed of germination-aid in selection and evaluation for seedling emergence and vigor. Crop Science 2: $176-177$.

29. Nelson C.J. (1996). Allelopathy in cropping systems. Agronomy Journal 88: 991 - 996.

30. Olefsdotter M., Navarez D. \& Moody K. (1995). Allelopathic potential in rice (Oryza sativa L.) germplasm. Annals of Applied Biology 127: 543 - 560. 
DOI: http://dx.doi.org/10.1111/j.1744-7348.1995.tb07611.x

31. Reigosa M.J., Sanchez-Moreiras A. \& Gonzalez L. (1999). Ecolophysiological approach in allelopathy. Critical Reviews in Plant Science 18: 577-608.

32. Rice E.L. (1984). Allelopathy, $2^{\text {nd }}$ edition, pp. 422. Academic Press, Orlando, USA.

33. Rice E.L. (1995). Biological Control of Weeds and Plant Diseases: Advances in Applied Allelopathy, pp. 448. University of Oklahoma Press, Oklahoma, USA.

34. Valverde B.E., Riches C.R. \& Caseley J.C. (2000). Prevention and Management of Herbicide Resistant Weeds in Rice, pp. 25 - 30. S.A Grafos, Cartago, Costa Rica.
35. Wathugala D.L. (2014). A review of nutraceutical and medicinal properties of Rice (Oryza sativa L.). Proceedings of the International Symposium on Minor fruits and Medicinal Plants, pp. 85 - 97. 20 December 2013, Faculty of Agriculture, University of Ruhuna, Mapalana, Kamburupitiya.

36. Weston L.A. (1996). Utilization of allelopathy for weed management in agro-ecosystems. Agronomy Journal 88: $860-866$.

37. Xuan T.D., Tsuzuki E., Tawata S. \& Khanh T.D. (2004). Methods to determine allelopathic potential of crop plants for weed control. Allelopathy Journal 13: 149 - 164. 